GIS - 理論と応用

Theory and Applications of GIS, 2016, Vol. 24, No.2, pp.73-84

【原著論文】

\title{
Parameter Smoothing Specification in Bayesian Geographically and Temporally Weighted Regression: Case Study of Analyzing Spatio- temporal Distribution of Population in Tokyo Metropolitan Area
}

\author{
Sajad Alipoureshliki ${ }^{*}$, Toshihiro Osaragi ${ }^{* *}$ and Takuya Oki ${ }^{* *}$ \\ ベイズ地理的時間的加重回帰におけるパラメータ平滑化手法 \\ 一首都圈における滞留者分布と土地利用を分析対象としたケーススタディー
}

アリプレシリキサジャド*・大佛俊泰 $* *$ ・沖拓弥 $* *$

\begin{abstract}
BGTWR）を用いてデータに備わる 時間的パターンを検出する際に，周期関数を用いてパラメー夕を平滑化する手法を提案 した。具体的には，まず，回帰係数間の時間的関係の長さ，傾向，および，周期性を調 整するためのパラメータ・セットを考案し, 異なる平滑化関数の形状を同一の基準を用 いて比較した。次に, 本手法の適用例として,パーソントリップ調査と細密数值情報 $(10 \mathrm{~m}$ メッシュ土地利用）のデータを用いて, 首都圈における住宅と商業施設の滞留者分布の 関係をBGTWRにより分析した。BGTWRを用いることで，非べイズモデルと比較して， 要約統計量のばらつきは小さく, 安定した結果を得ることが可能である。また, ベイズ 情報量基準（BIC）の值に基づき平滑化手法を比較すると, 本稿で提案した平滑化手法は, 他の手法と比較して最も良い結果を示した。さらに, 得られた回帰係数の $\mathrm{t}$ 值の時空間 分布を視覚化することで, 分析対象地域における滞留人口分布の時空間的特性は非べイ ズモデルよりも平滑化され, 滞留人口の地理的な拡散現象の理解がより容易になること を示した。
\end{abstract}

Keywords: Bayesian Geographically and Temporally Weighted Regression（ベイズ地理的時 間的加重回帰)，Gibbs sampling（ギブスサンプリング）, Parameter smoothing relationship（パラメータ平滑化）, Tokyo Metropolitan Area（首都圈）

\section{Introduction}

Most processes in environmental and ecological sciences behave in such a way that the process cannot be completely described by deterministic rules (Clark and Gelfand, 2006). Consequently, inference from data is plagued by inconsistent empirical estimates and uncertainty associated with modeling. The Bayesian approach is a statistical tool used for data analysis to integrate available information and empirical data to quantify uncertainty in parameters (Ascough et al., 2009). Bayesian modeling techniques through Markov chain Monte Carlo (MCMC) simulation provide a flexible means for describing even subtle patterns in data and combine complex models with external knowledge (Banerjee et al., 2004). Bayesian treatment has a great many advantages over the non-parametric locally regression model. First, it leads to overcome the problem of dependent samples and draw valid inferences using Gibbs sampling. The Gibbs sampler does not require independent sample and relies on the conditional distribution of parameters to carry out draws during sampling. Second, it allows modelers to produce estimates which are robust against aberrant observations, and finally it incorporates subjective prior information

* 学生会員 東京工業大学大学院情報理工学研究科 (Tokyo Institute of Technology)

** 正会員 東京工業大学環境・社会理工学院（Tokyo Institute of Technology）

干 152-8552 東京都目黑区大岡山 2-12-1 Tel. 03-5734-3162 
as an explicit specification of the relationship used to smooth the parameters (Subedi, 2012).

The local regression model relies on the theory that the relationships between the variables are not constant over the space. Gelfand et. al, (2003) suggested a Bayesian approach of spatially varying coefficients (SVCP) to build regression model. They offered an extension to generalized linear model for spatio-temporal data to explain (log) selling price of single family houses in Baton Rouge, Louisiana. The applications of Bayesian Geographically Weighted Regression (BGWR) have exploded into a wide range of study fields including real state and regional science. Lesage (2004) demonstrated the application of BGWR methods to predict neighborhood crime incidents using the household income and house value as the explanatory variables. Furutani (2004) used BGWR to estimate land prices in Yokohama. More recently, Gargallo and Salvador (2012) applied BGWR to real estate markets in the city of Zaragoza, Spain. In Geographically and Temporally Weighted Regression (GTWR) introduced by Huang et al. (2008), both spatial and temporal information was integrated to capture spatial and temporal heterogeneity. This model has the advantage of overcoming the typical problem for local models due to smaller samples than global approaches. Such extension usually treats time as an added spatial dimension, hence enlarges the twodimensional geographic space to the three-dimensional geographic-time space.

Similar to BGWR, Bayesian Geographically and Temporally Weighted Regression (BGTWR) uses informative priors to provide predictions under the posterior model and conceptually provides an intuitive approach to dealing with model uncertainty. In case of BGTWR, though the effects of outliers in space and time on the estimation of neighborhood's parameters are similar, usually there is a different pattern of spatio-temporal relationships and the temporal pattern is typically distinct from the spatial case where the observations relate to geographical locations (Yu, 2012).
The major contribution of this paper is an introduction of spatio-temporal parameter smoothing specification, as prior information to show how spatio-temporal dependence among observations is conceptualized. The periodic form of the exponential family function is introduced so that the model can be applied to global, long-term problems, where a massive data set is available. Our approach is couched in the context of the "scale" and "shape" of the Parameter Smoothing Relationship (PSR) and enables us to capture general systematic changes over time by setting two basic components of the trend and seasonality. To illustrate the method, we focused on parameter smoothing schemes based on spatio-temporal distance decay functions. We obtained the posterior inference from conditional probability distributions on parameters of the model and carried out a set of comparisons to validate the proposed approach. We applied our model to analyze the relationship between the distribution of population inside residential and commercial buildings in Tokyo Metropolitan Area (TMA).

The structure of the paper is as follows: Section 2 provides a brief introduction of BGTWR and options made in the parameter smoothing specification. In section 3 , we briefly describe the observed data, a summary of data preprocessing and setting parameters of the models. Section 4, demonstrates the results of the model, including mapping t-values of the regression coefficients, model assessment and evaluation. The concluding section presents a brief critique of the research and offers some thoughts on the future direction it might take.

\section{BGTWR overview}

BGTWR is a Bayesian framework of GTWR model which contains a heteroscedastic disturbance structure in the expansion relationship. In BGTWR, the nonstationarity parameter estimates are accounted by constructing the spatio-temporal $n \times n$ weight matrix $W_{M i}$, based on a distance function determined from $\left(p_{x i}\right.$, $\left.p_{y i}, p_{t i}\right)$ coordinates between observation $i$ and all other 
observations:

$$
W_{M i}=\left[\begin{array}{cccc}
w_{M i 1} & 0 & \ldots & 0 \\
0 & w_{M i 2} & & 0 \\
\vdots & \vdots & \vdots & 0 \\
0 & 0 & & w_{M i n}
\end{array}\right]
$$

These weights vary with $i$, which distinguishes BGTWR from traditional weighted least squares where the weighting matrix is fixed. The Bayesian treatment of GTWR is an extension of Lesage (2004) for the spatiotemporal application. The model is expressed as:

$$
\begin{aligned}
& \tilde{y}_{i}=W_{M i}^{1 / 2} y, \\
& \tilde{X}_{i}=W_{M i}^{1 / 2} X \\
& \tilde{y}_{i}=\widetilde{X} \beta_{i}+\varepsilon_{i}, \\
& \beta_{i_{k \times 1}}=\left(w_{i 1} \otimes I_{p}, \ldots, w_{i n} \otimes I_{p}\right)_{k \times n k}\left(\begin{array}{c}
\beta_{(1)} \\
\vdots \\
\beta_{(n)}
\end{array}\right)_{n k \times 1}+u_{i_{k \times 1}} \\
& =J_{i} \gamma+u_{i} .
\end{aligned}
$$

In Eqs. (2) and (3) vector $y_{n \times 1}$ is the dependent variable, $X_{n \times k}$ is the matrix of independent variables, vector $\tilde{y}_{i_{n \times 1}}$ and matrix $\tilde{X}_{i_{n \times k}}$ are local values which are calculated based on $W_{M i}$. In terms of $W_{M i}$, different alternative functions (exponential, Gaussian or tri-cube) could be employed which contain a distance decay parameter and place more weight on neighboring sample observations (Huang et al., 2008). The term $w_{i j}$ in Eq. (5) represents a parameter smoothing specification that is normalized so that the row-vector $\left(w_{i 1}, \ldots, w_{i n}\right)$ sums to unity. Since the specification represents the parameters in a specific location among its neighborhoods (not itself), $w_{i i}$ sets to 0 . It is possible to employ similar or different functional forms for both spatio-temporal weights in Eqs. (4) and (5). In Eq. (5), $I_{p}$ is the identity matrix and the stochastic term $u_{i}$ represents prior uncertainty about the smoothing relationship. The column-vector $\beta$ s refers to all regression coefficients from neighboring observations and $\beta_{i}$ would force to a distance-weighted linear combination of it. The conditional posterior distribution of $\beta_{i}$ is a multivariate normal distribution shown in Eqs. (6), (7) and (8):

$$
\mathrm{p}\left(\beta_{i} \mid \ldots\right) \propto \mathrm{N}\left(\widehat{\beta}_{i}, \sigma^{2} R\right)
$$

$\hat{\beta}_{i_{k \times n}}=R \times\left(\widetilde{X}_{i}^{\prime} V_{i}^{-1} \tilde{y}_{i}+\widetilde{X}_{i}^{\prime} \widetilde{X}_{i} J_{i} \gamma / \delta^{2}\right)$,

$R=\left(\widetilde{X}_{i}^{\prime} V_{i}^{1} \widetilde{X_{i}}+\widetilde{X}_{i}^{\prime} \widetilde{X}_{i} / \delta^{2}\right)$,

where:

$\varepsilon_{i_{n \times 1}} \sim N\left[0, \sigma^{2} V_{i}\right], \quad V_{i}=\operatorname{diag}\left(v_{1}, v_{2}, \ldots, v_{n}\right)$,

$u_{i} \sim N\left(0, \sigma^{2} \delta^{2}\left(X^{T} W_{i} X\right)^{-1}\right)$,

$P\left\{\left[\frac{\varepsilon_{i}^{2}}{\sigma^{2}}+r\right] / v_{i} \mid \ldots\right\} \sim \chi^{2}(r+1)$.

The parameter $\delta^{2}$ in Eq. (7) acts as a scale factor to impose tight or loose adherence to the parameter smoothing specification. The distribution for the stochastic parameter $u_{i}$ in Eq. (10) allow individual parameters $\beta_{i}$ to vary by different amounts depending on their magnitude. In Eq. (11) $v_{i}$ represents the variance scaling parameters and $\varepsilon_{i}$ is the error of the model defined in Eq. (4). The implementation of the Bayesian model with a large hyperparameter $r$ leads to $V=I_{n}$ and estimates from ordinary GTWR. In special cases, where the estimates $v_{i}$ provide a diagnostic measure of inconsistency with data, the heteroscedastic prior is implemented using a low value for the hyperparameter $r$ (Lesage, 2004). To carry out the Gibbs sampling, we need to drive the conditional posterior distributions for each group of parameters $\beta_{i}, \sigma_{i}, \delta_{i}$ and $v_{i}$ in the model produced by having other parameters and make a large number of passes to collect a large sample of parameter values from which we construct our posterior distributions (for details of Gibbs sampling see Congdon, 2006).

\section{1. $P S R$ in BGTWR}

In BGTWR, PSR defines a relationship among the local parameters and unifies the parameter estimation process across space and time (see Eq. (5)). This approach typically used to augment the sample data information and express one's beliefs about the distribution of parameters in probabilistic models. The advantage of PSR is to address 'weak data' problem since the effective number of neighbors defined by the 'pre-selected' bandwidth may be small (Subedi, 2012). 
There are different types of PSR such as spatio-temporal expansion, monocentric and contiguity models which define the different concepts of relationships. In distance parameter smoothing, it is assumed that parameters of the model are dependent on one another, based on Euclidean distances (Lesage, 2004). In Eqs. (12) and (13), $w_{s t}(d)$ express the exponential and Gaussian spatio-temporal smoothing relationship:

$$
\begin{aligned}
& w_{s t}(d)=e^{\frac{-d}{\theta}}, \\
& w_{s t}(d)=\frac{1}{\sqrt{2 \pi}} e^{\frac{-d^{2}}{2 \sigma^{2} \theta^{2}},}
\end{aligned}
$$

where $d$ is the distance vector and $\theta$ is the bandwidth of the model to produce a decay of influence with distance. $\sigma$ in Eq. (13) represents the standard deviation of distance vector $d$. For larger values of $\sigma, w_{s t}(d)$ is larger for observations. Such functions are called "fixed spatial kernels", indicating that the sample size used for defining relationships at the point $i$ is solely determined by parameter $\theta$ (Wang, 2011).

\subsection{The periodic form of temporal relationships for parameters in BGTWR}

A stochastic model for temporal data will generally reflect the fact that observations close together will be more closely related than observations further apart (Bisgaard and Kulahci, 2011). The most common patterns for the weight of temporal data are trend and seasonality. Trend generally has a linear or quadratic form which often downweight in time to take less effect on farther observations. Seasonality is a trend that repeats itself systematically over time (Box et. al, 1979). About the temporal smoothing in BGTWR, to be truly flexible, it is necessary to set parameters to keep the main characteristics of smoothing relationships and guaranty to capture underlying stochastic process. The parameters of such a function could be as follows:

- $\quad l$ : the parameter to calibrate the length of seasonality. This parameter regulates the weight through a time cycle.
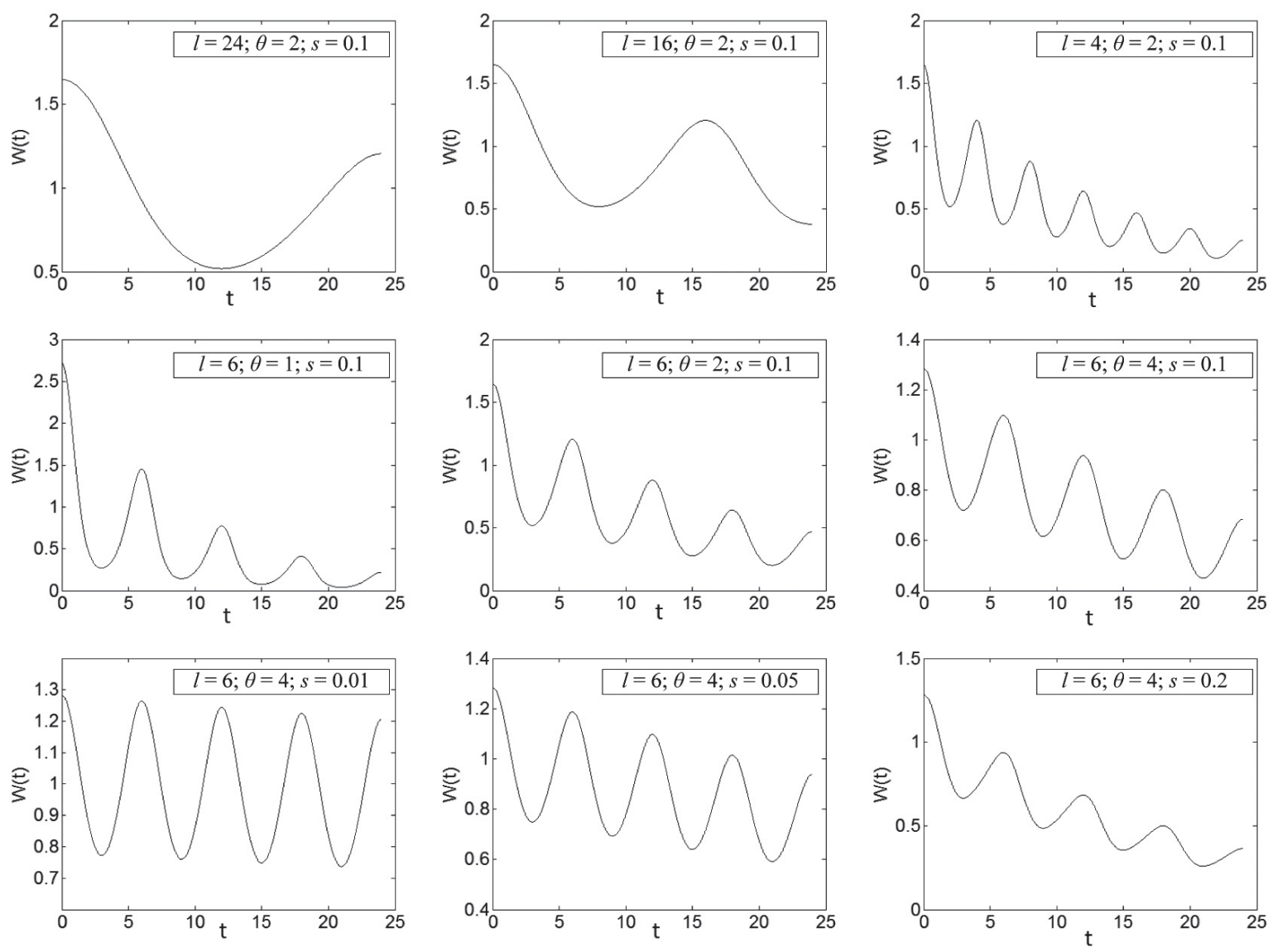

Fig. 1 Temporal smoothing scheme in BGTWR with a set of parameters 
- $\quad s$ : the parameter to decrease the amount of weight in a long-term (trend).

- $\quad \theta:$ the parameter for controlling time-distance decay during a single period of the season (bandwidth). By these conditions, we introduce the function below:

$$
w_{t}(t)=e^{\frac{\sin \left(\left(\frac{t}{l}+1\right) \frac{\pi}{2}\right) \frac{s \pi}{l} t+\frac{s}{2} \sin \left(\frac{t}{\pi^{l}}\right)}{\theta}} \quad \theta, l, s>0 .
$$

The main properties of $w_{t}(t)$ function are:

- $\lim _{t \rightarrow \infty} w_{t}(t)=0$,

- $\quad \frac{d}{d t} w_{t}(t)=0 \quad t=k \times l / 2, k=0,1,2, \ldots$

and $w_{t}(t)$ has local maximums in $t=k \times l$ and local minimums in $t=(2 k+1) \times l / 2$. Also the highest value of $w_{t}(t)$ located at $t=0$. Fig. 1 illustrates $w_{t}(t)$ by a different set of parameters.

Typically, cross-validation (CV) method is used to optimize the bandwidth or number of neighbors for weight functions (Farber and Pa'ez, 2007; Subedi, 2012). Employing $\mathrm{CV}$ score for the periodic model needs to optimize $l, \theta$ and $s$ simultaneously, which is extremely difficult and timeconsuming process. The alternative solution is to determine the best model by setting predefined parameters among a set of PSR candidates. In this case, PSR is employed as an exploratory tool and a general framework is established to define and evaluate models.

Since BGTWR relies on least square estimates, PSR does not lead us to predict values for the future (as it does in time series analysis and forecasting models). Also, PSR does not need to have a natural spatial/temporal ordering and data may have an irregular form. These models could be applied to compare different temporal patterns (as it is done in this paper) or specifically, same pattern in different terms for a specific area.

\section{Data and methods}

\subsection{Study area and data preprocessing}

The analysis was performed using Person Trip survey (PT data) conducted by Traffic Plan Council in 2008. PT survey is a questionnaire survey, for person's movement on a weekday. In PT data, 'Trip' means persons' movement for any purpose (such as commuting, working, shopping, etc.). In BGTWR, the dependent variable is the number of people inside commercial buildings ( $\mathrm{p}_{-}$ comm) and the explanatory variable is the number of people inside residential buildings (p_resid) for a specific position $\left(p x_{i}, p y_{i}, p t_{i}\right)$. Since there is a dynamic form of population movement, it is expected to have a significant spatio-temporal relationship for population between residential and commercial buildings. The study area focuses on Tokyo Metropolitan and 386 small zones around it (Fig. 2).

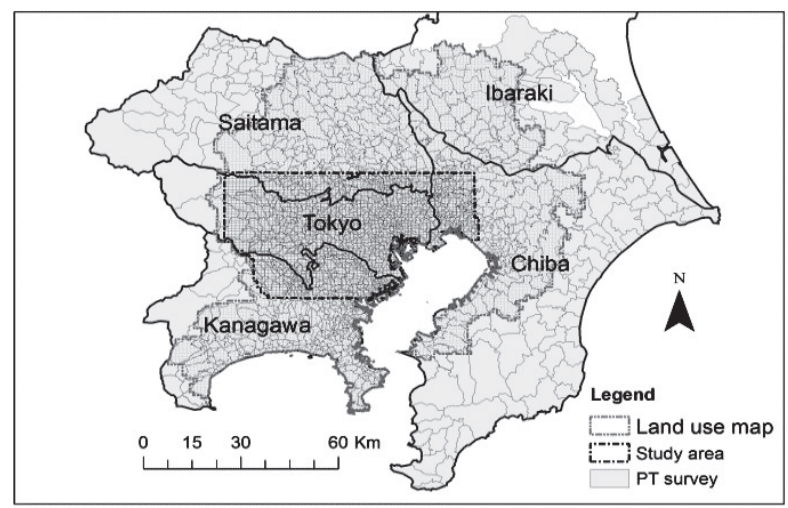

Fig. 2 Location of the study area, PT survey area and land use data

An arrangement of 24 GIS maps (each map refers to a specific hour) in ArcMap ${ }^{\mathrm{TM}}$ provided all necessary information to manage and explore spatio-temporal data. PT data were collected in lots of small zones (polygons) in irregular shapes covered the entire of the study area which the geometric center of polygons represented the spatial location of data. Since the size and shape of polygons were not uniform, the value of weight function in GTWR relied upon the geometry of them. Moreover, it is necessary to follow the assumption that the spatial density of population was consistent over the polygon which oversimplified the problem and produced bias estimations of parameters. To answer this issue, PT data were rescaled from polygons in irregular shapes to grids (Fig. 3). To do this, we utilized "Detailed Digital Map"

\footnotetext{
In the Detailed Digital Map, each $10 \mathrm{~m} \times 10 \mathrm{~m}$ grid is categorized into 15 land use types (i.e., residential, commercial/ business, industrial, agricultural, vacant, etc.) based on the aerial photograph images. In this paper, we used the map of 1994.
} 
for the study area which involved land use types data in $10 \mathrm{~m} \times 10 \mathrm{~m}$, and the total area of residential buildings in three codes was extracted as follows:

- Code 1: Low dense and low rise residential buildings ( 3 or less floors and the size of the plot is more than $100 \mathrm{~m}^{2}$ ).

- Code 2: High dense and low rise residential buildings ( 3 or less floors and the size of the plot is less than $100 \mathrm{~m}^{2}$ ).

- Code 3: High rise residential buildings (4 or more floors).

In the next step, the Detailed Digital Map was intersected to population map based on PT data and the population density of residential buildings was estimated by a linear regression model in sub regions inside polygons. In the linear regression, the three independent variables are the area of residential buildings clustered in three codes, and the dependent variable is the number of people in each sub region. Then, residuals of the regression model were calculated for each polygon and total amount of residuals were assigned to adjust the number of people in sub regions. In the last step, all estimated values were assigned to grids by the spatial intersection function from sub regions to provide PT data in a grid format. In case of the commercial population, we estimated the area of commercial buildings by intersecting land use map to sub regions and assigning population to polygons by the proportion of the total area of commercial buildings. Then we combined sub regions to grids. This procedure was executed for all 24 spatial

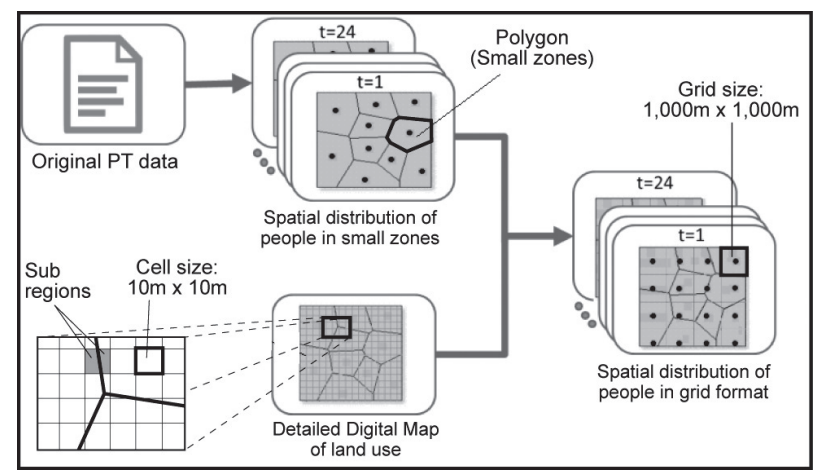

Fig. 3 Data preprocessing to extract number of people in a grid format (Alipoureshliki et. al, 2016) maps. Data consisted 8,409 grids (each grid size is 1,000 $\mathrm{m} \times 1,000 \mathrm{~m}$ ), totally 201,816 spatio-temporal positions. For each position, two values were recorded: the number of people in residential buildings (p_resid) and the number of people in commercial buildings (p_comm).

\subsection{Model implementation}

In local estimation, scale is an important factor in analyzing data. It holds key information in data modeling (Pawitan, 2010). In BGTWR, spatio-temporal heterogeneity is calculated by a distance function. However, space and time are generally measured in different units and need to be consideration (Huang et al., 2008). Since the spatial grid size was settled in whole of the space; we multiplied the time dimension to 1000 to have the same difference in all dimensions. Consequently, distance function between two positions $i$ and $j$ is explained as:

$$
d_{i j}=\sqrt{\left(u_{i}-u_{j}\right)^{2}+\left(v_{i}-v_{j}\right)^{2}+r\left(t_{i}-t_{j}\right)^{2}}
$$

where $t_{i}$ and $t_{j}$ are 1000 times bigger than their original values. As mentioned above, $r$ is the time-space ratio to calibrate the temporal distance among spatial planes.

In our model, we estimate spatio-temporal regression coefficients to predict $\mathrm{p} \_$comm $(y)$ by using p_resid $(x)$ after $\Delta t=1$ as follows:

$$
\begin{aligned}
& \tilde{y}_{i, \Delta t}=\beta_{0}\left(p x_{i}, p y_{i}, p t_{i}\right)+\beta_{1}\left(p x_{i}, p y_{i}, p t_{i}\right) \tilde{X}_{i}+\varepsilon_{i}, \\
& \beta\left(p x_{i}, p y_{i}, p t_{i}\right)=J_{i} \gamma+u_{i},
\end{aligned}
$$

where $\tilde{y}_{i, \Delta t}, \tilde{X}_{i}, J_{i}, \gamma$ and $u_{i}$ were defined in Eqs. (2), (3) and and $\Delta t$ could get any values from 0 to 23 . For example, $\Delta t=0$ means, $\mathrm{p} \_$comm is predicted by $\mathrm{p} \_$resid at the same time.

The region in which parameters were estimated is smaller than the original PT dataset (Fig. 2, study area). It includes 2,526 positions in space out of 8,409 (totally 60,624 spatio-temporal positions). We applied a bigger area to estimate coefficients at the border lines of Tokyo Metropolitan and its surroundings precisely. It provides detailed information and enables us to compare the pattern of relationship with its neighborhoods. 


\subsection{Setting PSR in BGTWR}

The main purpose of this paper is to analyze the efficiency of PSR for spatio-temporal data. Hence, to make a direct inference from the candidate models, we set a multiplicative form of space and time weight as follows:

$$
w_{s t}=w_{s} \times w_{t},
$$

where $w_{s}$ and $w_{t}$ are spatial and temporal weights, introduced in Eqs. (12), (13) or (14). They define different patterns of relationships between regression parameters $(\beta$ ) on the basis of Euclidian distance. Other types of functions might be employed to define relationships in which $w_{s t}$ gets an extremely complicated form and needs an elaborate approach to evaluate them.

In the next step, we must define a functional form of $w_{s}$ and $w_{t}$. About $w_{s}$, we rely on exponential distance decay function which its parameter $\theta$ is determined by cross-validation score as in the case of GTWR model and $d$ is the Euclidian distance (Table 1). Other parameters are estimated by MCMC algorithm. To evaluate the performance of temporal smoothing relationships, first we fix $w_{s}$ for all models, and then, set $w_{t}$. To have an adjustment in comparison of $w_{t}$ models, two parameters $a$ (regulator) and $\theta$ (bandwidth) are calculated for the specific values of $w_{t}: w_{t}^{\max }=1.0$ and $w_{t}^{\min }=0.1$.

Table 1 PSR specification in BGTWR

\begin{tabular}{|c|c|c|}
\hline$w_{s}$ & Function & Parameters \\
\hline Exp & $e^{\frac{-d}{\theta}}$ & $\theta$ : determined by $\mathrm{CV}$ score \\
\hline$w_{t}$ & Function & Parameters \\
\hline Linear & $a t+\theta$ & $\theta=w_{\max }, a=\frac{w_{\min }-w_{\max }}{T}$ \\
\hline Exponential & $a e^{\frac{-t}{\theta}}$ & $a=w_{\max }, \theta=\frac{T}{\ln \frac{w_{\max }}{w_{\min }}}$ \\
\hline Periodic & $a e^{\frac{\left.\sin \left[\frac{t}{1}+1\right) \frac{\pi}{2}\right]}{\theta}}$ & $\begin{array}{c}a=e^{\frac{\ln w_{\min }+\ln w_{\max }}{2}}, \theta=\left[\ln \frac{w_{\max }}{a}\right]^{-1} \\
, l=T\end{array}$ \\
\hline Gaussian & $\frac{a}{\sqrt{2 \pi}} e^{\frac{-t^{2}}{2 \sigma^{2} \theta^{2}}}$ & $a=\sqrt{2 \pi} w_{\max }, \theta=\left[\frac{T^{2}}{\ln w_{\max } 2 \sigma^{2}}\right]^{1 / 2}$ \\
\hline
\end{tabular}

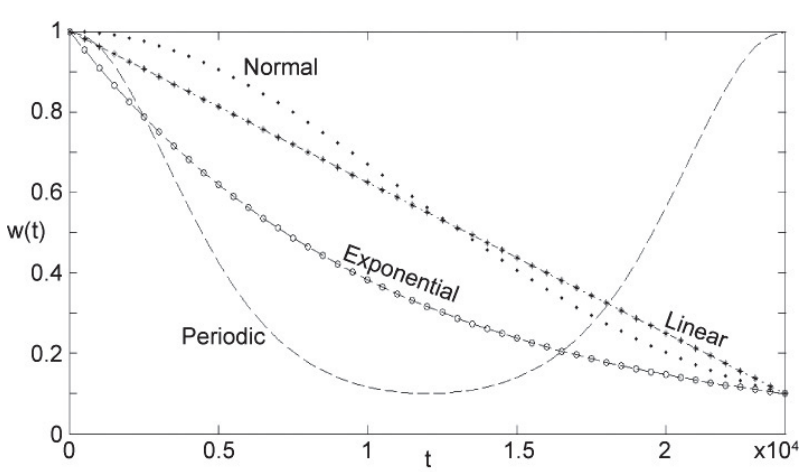

Fig. $4 w_{t}$ forms employed in BGTWR

To specify parameters in the periodic model, it is useful to follow a scenario which explains our beliefs about the dynamics of population distribution and its relationship with land use types. By this approach, we combine our prior assumption about parameters with data and update our knowledge in the presence of posterior estimates. According to the scenario, there is a transformation of the population from residential buildings to commercial buildings (by inverse direction) in the morning and evening. Consequently, it may have analogous in the relationship between population distribution and land use, which could be explained by the model.

We set $l=T=24,000$ to analyze data for 24 hours. Since we have no downweight for the trend in Eq. (14), $s$ assumed to be 0 and set other two parameters regulator and bandwidth based on $w_{t}^{\min }$ and $w_{t}^{\max }$. Table 1 demonstrates the functional forms and parameter settings for temporal smoothing models. It is possible to define scenarios for other PSR in Table 1, but we set the parameters by the same scale and employ them as an evidence of alternative relationships among parameters. Fig. 4 depicts $w_{t}$ among a single season for scaled data.

\subsection{Prior selection}

Choosing a prior selection is an important issue in Bayesian inference as it may be sensitive or robust to the inference of the choice of prior (Congdon, 2006). As explained in section 2, there are two factors at work to create a divergence between the GTWR and BGTWR estimates. One is $v_{i}$ parameter to capture non- 
constant variance over space and the other is PSR (Lesage, 2004). As mentioned earlier, in this paper, we focus on having an inference regarding how sensitive the model for four types of PSR. To illustrate this, we made a set of estimates for four types of models and posterior probabilities based on scaled $\delta$ in $0.05,0.1$, $0.5,1.0$ and 2.0 for $\delta$ from the diffuse prior. They reflect a fairly tight imposition of the prior for PSR. In case of hyperparameter $r$, five levels of coefficients (i.e., 4, 8, 10, 20, and 100) drowned from MCMC and the fit statistics indicated that the best model was obtained when the prior $r$ was at 10 . This value of $r$ produces estimates that are not very robust to heteroscedasticity or outliers. Thus, it helps us to have a straightforward result about the sensitivity of smoothing types and overcome the impact of outliers on the estimates, because we stochastically restrict the estimates and the impact of outliers will be diminished (Lesage, 2004).

We employed BGTWR to understand the structural characteristics of population movement based on land use types and provided a visual interpretation of trip distribution in the study area. Also by incorporating temporal data into the spatial model and compression of BGTWR with its non-Bayesian version, it is possible to provide a measurement scale to evaluate different level of uncertainty on the basis of predefined parameter of the models.

\section{Results of the analysis}

BGTWR was performed in Matlab ${ }^{\mathrm{TM}}$ on the basis of minimization of the $\mathrm{CV}$ score for bandwidth $(\theta=1150$ $\mathrm{m})$ in exponential function and the coefficient for the time dimension (ratio=0.9) in Euclidean distance. As mentioned in section 3; the dependent variable is the number of people inside commercial buildings ( comm) and the independent variable is the number of people inside residential buildings (p_resid) lagged by an hour. Four different types of PSR in a different level of tightness were applied and regression coefficients, t-value and other useful information were extracted.

\subsection{Model assessment and evaluation}

Table 2 demonstrates global statistics for GTWR, GTWR $_{\text {Per }}$ (periodic form of temporal weight) and BGTWR models. The diffuse value is calculated on the basis of non-informative prior and it corporates to scaled $\delta$. All four BGTWR models are based on a hyperparameter $r=10$ referring a heteroscedastic prior. As explained in section 3.2, different amounts of tightness are calibrated on the basis of scaled $\delta$. The diffuse prior for the relationships produced estimates for $\delta$ equal to 7.78 for the exponential, 8.07 for Gaussian, 7.74 for linear and 10.39 for periodic priors. These values indicate that the sample data are relatively consistent with all PSRs. In Table 3, MSE is the mean square error. In GTWR $_{\text {Per }}$ and GTWR, the amount of MSE is lower than BGTWR models; and in BGTWR, the periodic PSR is the lowest among other methods.

Table 2 Global indicators for model comparison

\begin{tabular}{|l|c|c|c|}
\hline \multicolumn{1}{|c|}{ Model } & $\delta_{\text {diffuse }}$ & MSE & $\mathrm{R}^{2}$ \\
\hline GTWR & - & 6205.05 & 0.9501 \\
\hline GTWR $_{\text {Per }}$ & - & 5883.11 & 0.9569 \\
\hline BGTWR & 7.74 & 6625.6 & 0.9413 \\
\hline Linear & 7.78 & 6556.27 & 0.9428 \\
\hline Exponential & 10.39 & 6542.61 & 0.9430 \\
\hline Periodic & 8.07 & 6573.76 & 0.9424 \\
\hline Gaussian &
\end{tabular}

For $\mathrm{R}^{2}$, there is a relatively small difference in predictive performance among GTWR and BGTWR models where $\mathrm{R}^{2}=0.9501$ for GTWR and slightly lower for the BGWR. The lower values of $\mathrm{R}^{2}$ for Bayesian models are not surprising. GTWR overstates the precision of the estimates but the results of BGTWR are more consistent and more applicable for detection of changes in relationships with variables in time and space. However, $\mathrm{R}^{2}$ may not an applicable indicator to compare Bayesian and non-Bayesian of the similar models. Fig. 5 illustrates a Bayesian comparison of BGTWR models. 
A Bayesian information criterion (BIC) is a criterion for model selection among a final set of models. The model with lowest BIC is preferred (Preacher and Merkle, 2012).

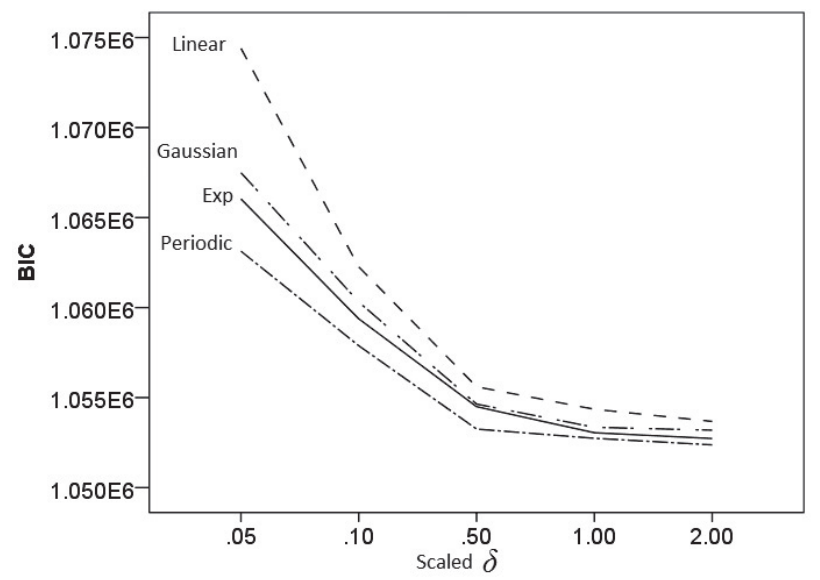

Fig. 5 BIC indicator to compare BGTWR models in scaled $\delta$

The scaled $\delta$ is the ratio of $\delta$ diffuse (demonstrated in horizontal axis) which were estimated as non-informative priors. Considering the trend of BIC in Fig. 5, as diffuse $\delta$ scaling down, the impact of PSR on BGTWR estimates produces a prior that imposes the PSR tighter on the model estimates. In contrast, using large values for scales will tend to eliminate PSR from the models. We see some evidence that all four models produced relatively similar estimates at scale $\delta=0.5,1.0$ and 2.0. Particularly, periodic and exponential models have the same values at scale $=2$. It is quite clear that the periodic model is the most consistent with the data as it receives slightly lower BIC. For the purpose of inference, $\triangle \mathrm{BIC}$ (the difference between BIC values among different models) is applied to compare PSR estimates. Typically for $\triangle \mathrm{BIC}>10$, the strength of the evidence against the model with higher BIC can be interpreted as "very strong" (Preacher and Merkle, 2012). Consequently, on the basis of $\triangle B I C$, there is very strong evidence that the periodic model is a single best model at least for scale $>0.5$ for $\delta$. However, the $\mathrm{BIC}$ is an increasing function of the sample size, which is big enough in our study; even for small amounts of difference among error estimations.
In addition to assessing posterior probabilities, we might look to the distribution of regression coefficients

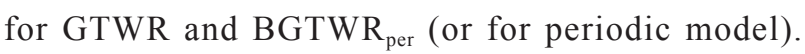
Table 3 reports the quartile and Std. Dev of regression coefficients. As it is shown, there are both positive and negative relationships between $\mathrm{p} \_$comm and p_resid. However, the quartile ranges reveal positive values are predominant for $\beta_{1}$ which infers that regions with more areas of residential buildings usually absorb more population for commercial buildings after an hour.

The standard deviation for GTWR and BGTWR per $_{\text {is }}$ 0.9294 and 0.8101 and the inter-quartile range for $\beta_{1}$ is 0.1705 and 0.1492 respectively. We would expect the robust Bayesian estimation for the standard deviation is smaller than that in GTWR. This partially also accounts for upward bias in t-values. Thus, the domain for t-values in BGTWR $_{\text {per }}$ also is narrower than that in GTWR.

Table 3 Summary of GTWR and BGTWR ${ }_{\text {per }}$ coefficient estimates

\begin{tabular}{|c|c|c|c|c|}
\hline \multicolumn{5}{|c|}{ GTWR } \\
\hline Variable & 1st Qu & Med & 3rd Qu & Std.Dev \\
\hline intercept & 162.77 & 1544.37 & 5159.69 & 35535.88 \\
\hline P_resid & -0.0081 & 0.0118 & 0.1624 & 0.9294 \\
\hline \multicolumn{5}{|c|}{ BGTWR per $_{\text {With } \delta=5}$ and $r=10$} \\
\hline intercept & 199.39 & 1598.47 & 5037.09 & 33425.88 \\
\hline P_resid & -0.0115 & 0.0111 & 0.1377 & 0.8101 \\
\hline
\end{tabular}

\subsection{Mapping t-values for GTWR and BGTWR $R_{\text {per }}$}

It is also instructive to draw maps of spatiallyvarying t-values for regression coefficients in order to yield a meaningful interpretation of results and visually distinguish comparisons between GTWR and BGTWR per Fig. 6 presents a map of t-values for $\beta_{1}$ in the study area at 7:00, 11:00 and 20:00 based on the commonly used significance threshold: non-significant (yellow and light green), 95\% (green and orange) and 99.5\% (red and blue) confidence level. Fig. 6-a clearly indicates that in the majority of TMA, the relationship between p_comm and $\mathrm{p}$ _resid is negative and significant at $99.5 \%$. Hence the regions with higher areas of commercial buildings (and lower areas of residential buildings) absorb more 
population after one hour. At this time, people usually have longer distance trips such as work, business or educational related and the residential population shifts to other types of buildings. Thus, the correlation between p_comm and p_resid are directly affected by land use types which are usually distributed negatively at spatial scale.

Fig. 6-b demonstrates t-values for $\beta_{1}$ at 7:00 for BGTWR. It indicates roughly similar relationships in comparison with the non-Bayesian ranges. In Fig. 6-c, the study area is clustered into two different sub-regions, given the range of the t-values. In the inner city of Tokyo, the relationship is significantly negative between p_resid and p_comm which predominantly is a function of the spatial distribution of commercial building with a regular stream of the population for the whole of TMA. In other areas, the relationship is significantly positive given the fact that population movement is affected by home activities such as daily shopping which usually are based on the shortest path. Consequently, the relationship between p_comm and p_resid are correlated at spatial scale. By comparing, in Fig. 6-c and Fig. 6-d there is not a considerable difference in the distribution of t-values, indicated the regional and localized spatial variability of the estimated coefficients by GTWR and BGTWR methods are very similar. It suggests a steady state pattern of population distribution at this hour.

In Fig. 6-e the spatial variations of t-values for GTWR at 20:00 have been mapped. As it is shown, there is a significant spatial heterogeneity for $\beta_{1}$ estimation. At this time, commercial buildings lose their population and residential buildings are being populated gradually, but the relationship is not constant across space. Fig. 6-f demonstrated a more distinguished map, as the study area roughly clustered into three sub-regions with different magnitudes and significant levels indicated the

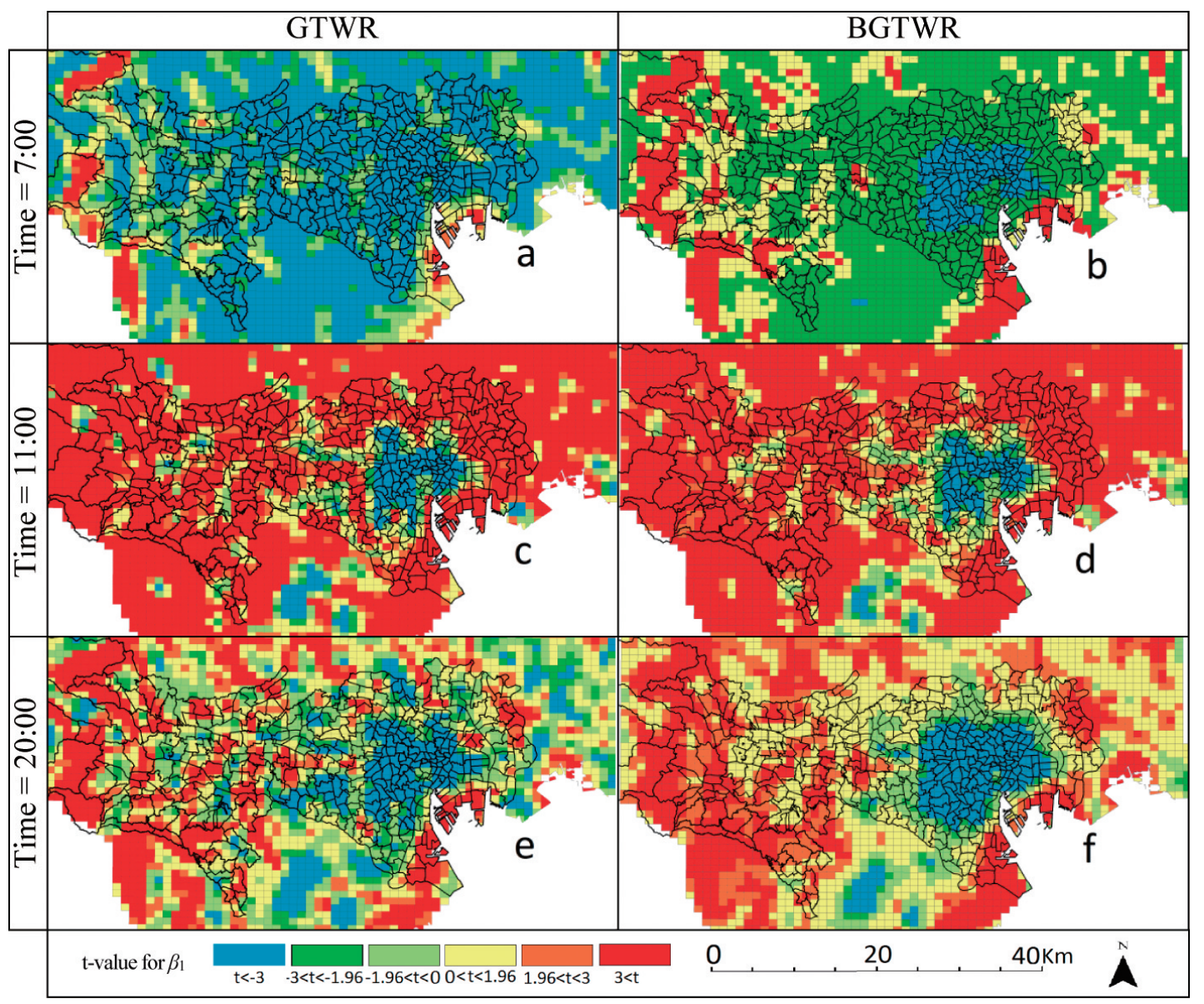

Fig. 6 Spatial variation of t-values for $\beta_{1}$ in GTWR and BGTWR ${ }_{\text {per }}$ with $\delta=5$ and $r=10$. 
relationships gradually changed from the center of Tokyo to the suburbs.

As it is shown in Fig. 6, BGTWR provides smooth maps of t-values derived from the posterior distribution of $\beta_{1}$ which are more consistent across space. This is an advantage of less sensitive to outliers and unifying approach in parameter estimation across observations. In mapping the distribution of parameter estimates and t-values generated from the models, BGTWR provides a continuous form of temporal variation which clustered spatially on the basis of specific regions. For example, Fig. 6-b, d, and $\mathrm{f}$ are more similar to each other than Fig. 6-a, c and e in the non-Bayesian model. It reveals the influence of periodic smoothing. In other hand, BGTWR provides clustered map in which significant and nonsignificant areas are more distinguishable. However, the difference between patterns in the morning and evening are bigger than those in the middle of the day due to a sudden shift of population movement in the morning and a gradual change in the afternoon. Hence, it needs to $\operatorname{set} \theta$ and assign lower values to downweight temporal relationship in the seasonal term.

\section{Conclusions and future work}

Building the local linear model and setting-up for Bayesian technique associated with efficient MCMC algorithms, BGTWR was applied to a real dataset and comparisons were made under several settings, including a set of PSR and hyperparameter $r$. This automatically took into account the prior probability and provided a diverse range, from a very robust model based on deep uncertainty to a more flexible model on the basis of noninformative priors associated with regression coefficients. Regardless of whether the results were indicative of perfect prediction in both models, BGTWR highlighted the spatio-temporal structure of population distribution and enabled us to examine our prior knowledge based on the evidence from data and produced interpretable results. Statistical summary of regression coefficients demonstrated a shorter range with a lower variation in
Bayesian approach. The t-values represented a smoothed map given the advantage of the periodic form by temporal relationship and exponential form by the spatial pattern.

In this paper, PSR was employed as an exploratory tool and comparative statistics were conducted to determine the fitness of the models. Due to the complexity of interpretation, we did not analyze the effect of outliers or heterogeneity of variance and to addressing this difficulty, relied on a specific value of hyperparameter $r$ and adjustment derived by tightness from PSR. The advantage of BGTWR, in this case, was to identify map clusters which sometimes not recognized clearly by a GTWR model due to the presence of outliers or disturbance in local variations. Also to depict the sensitivity of models given the amount of tightness, the BIC indicator was calculated on the basis of different levels of $\delta$ as diffuse prior. Results indicated that there is a negative relationship between the level of tightness and amount of sensitivity. Due to lack of sample points, the BGTWR model for PT data was employed for one cycle (24 hours) and in temporal PSR, the parameter to decrease the amount of weight in a long-term $(s)$ was not involved. Hence by having more cycles in the sample data and involving the long-term in PSR, the efficiency of the periodic form in comparison of other models could be shown much better. Also one advantage of the periodic model is to estimate the parameters in the boundaries of the study period. However, for the case study, the results of local estimations in BGTWR are not valuable to report because the population in commercial buildings is close to zero for most of the study area.

Further research needs to be done to uncover the exact nature of spatio-temporal heterogeneity or dominant patterns of model parameters. In our model, we assumed a simple form of PSR to directly infer from data by setting an evaluation method and compare the shape of smoothing at scale. It is an interesting topic to establish a comprehensive framework to evaluate a much broader class of PSR based on an explicit specification. In local 
regression models, the $\mathrm{CV}$ method is frequently used to determine the optimum value of $\theta$ which usually is over/ underestimated by the existence of outliers. One of the possible ways of improving the model performance could be devising a method to achieve a robust estimation of the bandwidth parameter and handle this problem.

\section{Reference}

Alipoureshliki, S., Osaragi, T. and Oki, T. (2016) Modeling the spatio-temporal relationships for the distribution of population with geographically and temporally weighted regression, Journal of Architecture and Planning, 81( 723), 113-120.

Ascough, J.C., Maier, H.R., Ravalico, J.K. and Strudley, M.W. (2009) ecological modeling, 219 (3-4), 383-399.

Banerjee, S., Carlin, B.P. and Gelfand, A.E. (2004) Hierarchical Modeling and Analysis for Spatial Data, Chapman and Hall, Boca Raton, FL, 451.

Bisgaard, S. and Kulahci, M. (2011) Time series analysis and forecasting by example, John Wiley and Sons Ltd, Oxford, 18.

Box, G. E. P., Hillmer, S. and Tiao, G. C. (1979) Analysis and Modeling of Seasonal Time Series, Neber press, 313.

Clark, J. S. and Gelfand, A. E. (2006) Hierarchical modelling for the environmental sciences: statistical methods and applications, Oxford University Press.

Congdon, P. (2006) Bayesian statistical modelling, John Wiley \& Sons Ltd, West Sussex, 12.

Farber, S. and Pa'ez, A. (2007) A systematic investigation of cross-validation in GWR model estimation: empirical analysis and Monte Carlo simulations, $J$. Geogr. Syst., (9), 371-396.

Furutani, T. (2004) Bayesian Geographically Weighted Regression model and its application for land price model estimation, Journal of the City Planning Institute of Japan, 39(2), 787-792.

Gargallo, P. and Salvador, M. (2012) A Bayesian geographically weighted regression model applied to real estate markets, International society for Bayesian analysis, Available at http://bayesian.org/node/2987.

Gelfand, A. E., Kim, H. J., Sirmans, C. F. and Banerjee, S. (2003) Spatial modeling with spatially varying coefficient processes, Journal of the American Statistical Association, 98(462), 387-396.

Huang, B., Wub, B. and M. Barryc, (20 010 ) Geographically and temporally weighted regression for modeling spatio-temporal variation in house prices, International Journal of Geographical Information Science, 24(3), 383-401

LeSage, J. P. (2004) A family of geographically weighted regression models. In: Anselin L, Florax RJGM, Rey SJ (eds) Advances in spatial econometrics. Methodology, tools and applications. Springer, Berlin Heidelberg New York, 241-264.

Pawitan, G. (2010) Spatial distribution of poverty at different scales, International journal of economics and finance studies, 2(1).

Preacher, K. J. and Merkle, E. C. (2012) The problem of model selection uncertainty in structural equation modeling, Psychological Methods, 17(1), 3.

Subedi, N. (2012) Local modeling of tree crown area using Bayesian Geographically Weighted Regression, Ph.D Thesis, University of New York, Syracuse, New York, 4,61.

Wang, Y. (2011) Anticipating land use change using geographically weighted regression models for the discrete response, Transportation Research Record, 2245, 111-123.

Yu, D. (2012) Exploring spatiotemporally varying regressed relationships, the geographically weighted panel regression analysis, Photogrammetry, Remote Sensing and Spatial Information Sciences, 38, 2.

（2016年1月19日原稿受理，2016年5月28日採用決 定，2016年7月29日デジタルライブラリ掲載) 